\title{
METODOLOGIAS ATIVAS DE ENSINO/APRENDIZAGEM: DIFICULDADES DE DOCENTES DE UM CURSO DE ENFERMAGEM
}

\author{
ACTIVE TEACHING/LEARNING METHODOLOGIES: DIFFICULTIES FACED BY THE FACULTY OF A \\ NURSING COURSE
}

\section{METODOLOGÍAS ACTIVAS DE ENSEÑANZA/APRENDIZAJE: DIFICULTADES DE DOCENTES DE UN CURSO DE ENFERMERÍA}

\author{
Simone Karine da Costa Mesquita ${ }^{1}$ \\ Rejane Millions Viana Meneses ${ }^{2}$ \\ Déborah Karollyne Ribeiro Ramos ${ }^{3}$
}

Resumo O estudo objetivou identificar as dificuldades vivenciadas pelos docentes na implementação de metodologias ativas no curso de graduação em enfermagem de uma instituição federal localizada no Rio Grande do Norte. Tratou-se de pesquisa exploratório-descritiva com enfoque qualitativo. As entrevistas semiestruturadas foram aplicadas a vinte sujeitos nos meses de agosto e setembro de 2011 e, posteriormente, analisadas seguindo pressupostos da análise de conteúdo. As principais adversidades elencadas pelos sujeitos da pesquisa foram agrupadas em três categorias de análise: problemas curriculares como empecilho para a aplicação de metodologias ativas de ensino/aprendizagem; resistência do docente em implementar metodologias ativas de ensino/aprendizagem; e dificuldade de compreensão da aplicabilidade das metodologias ativas de ensino/aprendizagem na prática docente. Diante de tais dificuldades, fez-se necessário introduzir novas formas de organizar e produzir o conhecimento, uma vez que a utilização de metodologias ativas poderia favorecer a formação de sujeitos com visão ampliada de saúde, ativos e comprometidos com a transformação da realidade. Compreender a utilização de metodologias ativas é fundamental para atender aos pressupostos do paradigma educacional contemporâneo.

Palavras-chave educação; metodologias ativas; ensino de enfermagem; formação do enfermeiro.

\begin{abstract}
The study aimed to identify the difficulties experienced by faculty in the implementation of active methodologies in the undergraduate course in nursing at a federal institution in the state of Rio Grande do Norte, Brazil. This was an exploratory and descriptive survey using a qualitative approach. The semi-structured interviews were applied to twenty subjects in August and September 2011 and, subsequently, analyzed pursuant to content analysis assumptions. The main adversities listed by the research subjects were grouped into three analysis categories: Curricular issues as an impediment to the application of active teaching/learning methodologies; professor resistance to the implementation of active teaching/learning methodologies; and difficulty in understanding the applicability of active teaching/learning methodologies in the teaching practice. Faced with such difficulties, it was necessary to introduce new ways to organize and produce knowledge, since the use of active methodologies could favor the training of subjects with an enhanced view on health who are active and committed to the transformation of reality. Understanding the use of active methodologies is critical to meeting the assumptions of the contemporary educational paradigm.
\end{abstract}

Keywords education; active methodologies; nursing education; nurse training. 


\section{Introdução}

Na nova ordem mundial, são notórias as mudanças nos aspectos social, ético, econômico e político da sociedade pós-moderna, as quais atingem de modo incisivo o ensino superior, exigindo uma nova visão de formação profissional para fazer frente às necessidades do paradigma educacional da atualidade. Nesse contexto, a tendência pedagógica contemporânea deve favorecer o desenvolvimento profissional voltado para as dimensões éticas e humanísticas, com capacidade de reflexão, crítica e atenção às necessidades da população, a fim de transformar realidades.

Diante de tais argumentos, uma crescente intenção pela busca de métodos inovadores de ensino-aprendizagem emerge, de modo a contemplar as reais necessidades da sociedade hodierna, ultrapassando os limites do treinamento puramente técnico para, efetivamente, alcançar a formação do homem como um ser histórico, inscrito na dialética da ação-reflexão-ação (Mitre et al., 2008). Para Cyrino e Toralles-Pereira (2004), o problema educacional é entendido como um tradutor/refletor da realidade, um desafio à aprendizagem, um obstáculo a ser superado.

Nesse contexto, emergiram as metodologias ativas entendidas como um modelo de formação profissional mais condizente com os princípios e necessidades da atual política de saúde (Marin et al., 2010). Os métodos de aprendizagem ativa ancoram-se na pedagogia crítica, a qual parte de uma crítica de ensino tradicional e propõe-se a usar as situações-problema como um estímulo à aquisição de conhecimentos e habilidades (Cyrino e Toralles-Pereira, 2004).

As chamadas metodologias ativas, no campo da formação profissional em saúde, vêm sendo embasadas em duas abordagens problematizadoras: pedagogia da problematização e aprendizagem baseada em problemas (Marin et al., 2010). No tocante à produção de conhecimento, relacionada às metodologias ativas no campo da saúde, em particular na enfermagem, merecem destaque as publicações de Aguilar-da-Silva e Rocha Junior (2010) e Heck e colaboradores (2009).

Para Wall, Prado e Carraro (2008), a implementação de metodologias ativas nos cursos de graduação implica o enfrentamento de múltiplos desafios, desde os estruturais (organização acadêmica e administrativa das instituições e cursos) até os de concepções pedagógicas (crenças, valores e modos de fazer) de professores e alunos. Os autores acrescentam que para ocorrer a inovação educativa é necessário que haja novos patamares de organização e produção do conhecimento em conexão com os desafios da prática e com as lutas que emergem em diferentes campos sociais.

Diante do exposto, o presente estudo buscou identificar as dificuldades vivenciadas pelos docentes na implementação de metodologias ativas no 
curso de graduação em enfermagem de uma instituição federal localizada no Rio Grande do Norte. Para tanto, além do respaldo em pensamentos de teóricos da educação brasileira, recorreu-se às experiências de ensino narradas por docentes da instituição pesquisada, os quais são mediadores do aprendizado dos futuros profissionais de enfermagem.

\section{Percurso metodológico}

Este artigo4 é um recorte da pesquisa de mestrado intitulada Abordagens pedagógicas na formação de enfermeiros: perspectivas de docentes de enfermagem (Mesquita, 2012). O estudo de campo foi do tipo exploratório e descritivo, com abordagem qualitativa, realizado em uma instituição federal localizada no município de Natal, capital do Rio Grande do Norte.

Participaram da pesquisa vinte sujeitos, todos enfermeiros, dos quais $55 \%$ apresentavam como maior titulação o doutorado e $45 \%$ o mestrado. O método adotado para a seleção dos sujeitos do estudo foi o não probabilístico por conveniência, considerando o critério de acessibilidade.

Adotaram-se como critérios de inclusão: ser docente (efetivo ou substituto) alocado no Departamento de Enfermagem da instituição lócus da pesquisa; ministrar disciplinas teórico-práticas de enfermagem; e ter, no mínimo, um ano de experiência na docência.

As informações foram coletadas no segundo período letivo, ou seja, de agosto a setembro de 2011, mediante a utilização da técnica de entrevista semiestruturada. O material empírico foi analisado à luz do referencial teórico-metodológico da análise de conteúdo proposta por Bardin (2010).

Por tratar-se de pesquisa envolvendo seres humanos e acatando os preceitos éticos e legais contidos na resolução n. 196/96 do Conselho Nacional de Saúde, o presente estudo foi encaminho ao Comitê de Ética em Pesquisa da Universidade Federal do Rio Grande do Norte, recebendo parecer favorável por meio do protocolo n. 416/2011 e certificado de apresentação e apreciação ética (CAAE) n. 0131.0.051.000-11.

\section{Dificuldades na utilização de metodologias ativas na prática pedagógica}

A análise do material empírico proveniente das entrevistas indicou dificuldades na utilização de metodologias ativas por parte dos docentes. As principais dificuldades elencadas pelos referidos profissionais foram distribuídas em três categorias de análise: problemas curriculares como empecilho para a aplicação de metodologias ativas de ensino/aprendizagem; resistência de docentes em implementar metodologias ativas de ensino/aprendizagem; e 
dificuldade de compreensão da aplicabilidade de metodologias ativas de ensino/aprendizagem na prática docente.

\section{Problemas curriculares como empecilho para a aplicação de metodologias ativas de ensino/aprendizagem}

No tocante aos problemas relacionados aos currículos, encontramos relatos referentes à falta de tempo e à desarticulação entre os conteúdos curriculares e a realidade. Com referência ao tempo, o docente 3 disse:

Espera-se que esses currículos novos propiciem na sua organização (...) horas que sejam suficientes para levar o aluno a fazer uma reflexão, utilizando metodologias ativas (...) não encontro um horário para fazer uma aplicação de um conteúdo que demande leitura, que demande exercícios em sala, que demande feedbacks mais participativos, com possibilidades de mais de um ou mais de dois encontros para um tema. São componentes curriculares com cargas horárias enormes (D3).

Segundo Saviani (2010), existem três exigências atuais para a instituição formadora de cidadãos críticos e participativos. Dentre elas está a exigência de um currículo correspondente em termos da seleção dos conteúdos, distribuição do tempo, dos métodos de ensino/aprendizagem e materiais didáticos. Em outras palavras, o conteúdo solicitado deve ser coerente com o tempo exigido. Observa-se, portanto, uma necessidade de organização curricular; alguns conteúdos exigem maior atenção por parte do docente, requerendo tempo maior para serem bem trabalhados com os discentes.

(...) um conteúdo que não foi bem selecionado, talvez falte alguns importantes e haja excessos de uns menos importantes. Talvez isso seja consequência de mudanças pouco trabalhadas (D4).

Quanto aos conteúdos ministrados, eles devem ser relevantes para o aprendizado do discente; especificamente na enfermagem, esses conteúdos devem ser articulados com a realidade social. Para Saviani (2010), os conteúdos irrelevantes abrem espaço para sobrecarregar os currículos, tornando as matérias curriculares desinteressantes. Desse modo, os alunos começam a encarar o ensino como uma obrigação carente de sentido, da qual eles buscam livrar-se assim que possível. Acredita-se que nesse momento os docentes conseguem lidar criticamente com os conhecimentos disponíveis, distinguindo entre o que é relevante e o que não é, ganhando condições de produzir seus próprios conhecimentos. Assim, o seu ensino deixa de ser mera transmissão, incorporando também uma contribuição original (Saviani, 2010). 
Os conteúdos devem ser significativos, precisam ser apresentadas situações-problemas para provocar o interesse dos alunos, devendo-se respeitar a cultura e o conhecimento prévio deles. Libâneo (2009) acredita ser necessário propor conteúdos e modelos compatíveis com as experiências dos discentes, para que eles se mobilizem para uma participação ativa. O ensino, quando desarticulado da realidade, focaliza o conteúdo por si só, gerando visão distorcida da realidade e alienando os alunos de sua verdadeira responsabilidade profissional. Esse tipo de ensino cria a dissociação entre o pensar e o fazer, limitando o questionamento, uma vez que o que importa é o volume produzido no menor tempo. Portanto, esses conteúdos devem ser superados, a fim de fornecer respostas para melhor compreensão de vida (Hengemühle, 2008).

\section{Resistência de docentes em implementar metodologias ativas de ensino/aprendizagem}

Outra dificuldade abordada pelos docentes da graduação em enfermagem foi a resistência em modificar sua prática, como mostram as narrativas a seguir:

Tenho determinada resistência a essas novas metodologias (D11).

Tenho uma formação tão tradicional, tão arraigada, em geral tenho dificuldade de mudar (D1).

(...) a gente vem de um sistema antigo, mas a gente tenta evoluir (...) mas não é fácil, não (D8).

Não é uma tarefa fácil, não é só você colocar no currículo que vai adotar uma pedagogia problematizadora. Como eu falei, ela requer mudança de hábito, de costume, de prática em sala, de você querer se abrir para o novo e para mudança (D2).

Pelas falas dos participantes da pesquisa pôde-se perceber que as práticas docentes estão diretamente ligadas a modelos antigos, à forma como os próprios professores aprenderam, refletindo dificuldades na adesão de novas práticas. Cunha (2006) afirma que muitas das práticas docentes atuais estão relacionadas às experiências vividas como alunos. Os docentes absorveram visões de mundo, concepções epistemológicas, posições políticas e experiências didáticas. Por meio delas foram formando e organizando, de forma consciente ou não, seus esquemas cognitivos e afetivos, que acabaram dando suporte para a sua futura docência. Intervir nesse processo de naturalização profissional exige uma energia sistematizada de reflexão, baseada na 
desconstrução da experiência. Os sujeitos professores só alteram suas práticas quando são capazes de refletir sobre si e sobre sua formação (Cunha, 2006).

No contexto atual, esse modelo tradicional restringe o processo de ensino, escondendo as concepções que os alunos trazem consigo. Assim, os docentes não se encontram diante de uma opção, mas de uma necessidade de mudança (Rosa, 2007). Para que os novos aprenderes galguem seu lugar, é necessária uma mudança de cada vez. Para isso, o primeiro passo seria a compreensão dos novos paradigmas em educação; formar discentes que reconheçam as diferentes perspectivas na concepção das questões de saúde e nos modos de atuar do profissional, possibilitando um agir mais cuidador (Bulgraen, 2010).

Nessa conjuntura, cabe aos docentes refletirem sobre seu papel na educação e sobre a finalidade de educar e, assim, cumprir a tarefa de romper com velhas crenças, cessar com o dogmatismo das práticas educativas, substituir o autoritarismo por humildade e disposição para a obediência (Rosa, 2007).

\section{Dificuldade de compreensão da aplicabilidade das metodologias ativas de ensino/aprendizagem na prática docente}

Alguns docentes relataram como dificuldades para a implementação de metodologias ativas de ensino/aprendizagem problemas referentes à compreensão da aplicabilidade de tais metodologias. Vejamos os recortes seguintes:

(...) a gente não consegue aprender. Estou falando de mim, como docente de muito tempo (D4)

Então, assim, você quer, mas você não sabe como; às vezes você lê, lê, lê, mas você não tem direcionamento (D6).

Na realidade, muitos docentes têm dificuldades de compreender a complexidade de uma proposta transformadora e os requisitos teóricos para discriminar e distingui-la das demais tendências pedagógicas (Saviani, 2010). No entanto, é de fundamental importância o conhecimento das tendências pedagógicas para nortear a prática do professor e, dessa forma, propiciar um agir docente com competência, responsabilidade e compromisso (Rosa, 2007).

Afirmações propaladas por Freire (2010) ressaltam a necessidade de o docente assimilar os princípios que norteiam a atividade do professor em direção à autonomia. É necessário que o profissional tenha uma reflexão crítica do exercício da docência para a valorização da profissão docente, dos saberes dos professores, do trabalho coletivo destes e das instituições como espaços de formação contínua, bem como para o reconhecimento do professor como investigador e produtor de conhecimento. Essa atitude de reflexão so- 
bre sua própria prática, de forma sistemática e objetiva, orientada por um suporte teórico-metodológico, permite ao professor repensar e problematizar a ação educativa que desenvolve no decorrer das aulas, no que diz respeito a saberes, técnicas, metodologias e estratégias interativas para que, de fato, ocorra a aprendizagem (Freire, 2010).

Com o intuito de suprir as necessidades de compreensão de pedagogias, da metodologia e dos métodos que favorecem uma aprendizagem mais crítica, reflexiva e articulada com a realidade, docentes relataram a necessidade de encontros pedagógicos:

Acho que deveria ter, assim, cursos estimulando como fazer, porque às vezes você quer fazer, mas não sabe como faz (D7).

Encontros pedagógicos para colocar as dificuldades que os professores estão tendo para desenvolver sua prática pedagógica nesse novo currículo. O preparo pedagógico, atualização pedagógica do professor deveria acompanhar, e deveria ser contemplada também, paralelamente, junto a essas mudanças curriculares, porque muda os currículos e a prática docente continua (D5).

A pedagogia crítica não é uma concepção pedagógica fácil de ser trabalhada. Na verdade, eu acho que exige do professor uma certa capacitação (P13).

Alguns docentes expressaram a ideia de que a formação continuada deveria ser ofertada, indicando que se faz necessária a realização de cursos de capacitação para todos os envolvidos no processo educativo, visando formar um profissional ativo e preparado para as necessidades do mercado de trabalho contemporâneo.

A formação continuada deve levar, necessária e constantemente, aos processos de reflexões críticas, conscientes e plurais sobre a prática docente. Porque aprendemos, no mínimo, metodologias de investigação de nossas próprias práticas, gerando as autodescobertas que acabam por tornar mais ricas e movimentadas nossas atuações, já que a formação continuada é aprendizado que nunca termina, "um continuum que simboliza o eterno movimento que garante o equilíbrio universal" (Miranda, 2011, p. 29).

Nesse contexto, necessita-se que as instituições forneçam subsídios aos docentes para repensarem e modificarem sua prática educativa, considerando a necessidade de formar professores capazes de fazer brotar sujeitos críticos, reflexivos e questionadores, em resposta às necessidades da sociedade. Portanto, torna-se pertinente promover discussões mais aprofundadas na universidade acerca da possibilidade de transformação das ações educativas e da implementação de um ensino transformador como orientador dos processos de formação (Ponce de Leon e Silva, 2006). 
Alguns sujeitos relataram a existência de um curso preparatório para capacitação de docentes na instituição pesquisada, como mostra o relato a seguir:

Aqui nesta instituição são oferecidos alguns cursos preparatórios, como o programa de aperfeiçoamento, que se chama Programa de Aperfeiçoamento do Professor [PAP] (D18).

O curso PAP recentemente ofertado para todos os professores que estão ingressando na instituição, como é o meu caso, nós somos obrigados a participar desses cursos, mas, mesmo que não fosse obrigado, seria de extrema importância e é uma iniciativa da própria instituição, onde ele trabalha justamente essa questão pedagógica e essas metodologias transformadoras (D10).

O PAP da instituição na qual foi realizada a presente pesquisa oferecia atividades voltadas à formação do docente. No âmbito da enfermagem, são de extrema relevância cursos de capacitação profissional dos docentes, em particular aqueles que visam oferecer resultados de domínio didático-pedagógico para a formação de enfermeiros teórica e metodologicamente qualificados para o exercício dos serviços de cuidados e, concomitantemente, para o domínio de recursos didáticos e pedagógicos indispensáveis às práticas significativas no campo do saber cuidar.

No tocante às exigências quanto à formação docente, a Lei de Diretrizes e Bases da Educação (Brasil, 1996) aborda, no seu art. 61, como critérios para formação do educador:

Art. 61. A formação de profissionais da educação, de modo a atender aos objetivos dos diferentes níveis e modalidades de ensino e às características de cada fase do desenvolvimento do educando, terá como fundamentos: I - a associação entre teorias e práticas, inclusive mediante a capacitação em serviço; II aproveitamento da formação e experiências anteriores em instituições de ensino e outras atividades (Brasil, 1996, p. 1).

Desse modo, legalmente estatuído, fica explícito que a formação docente não exige apenas a conclusão de um curso superior; necessita-se, portanto, da busca por oportunidades de aperfeiçoamento, do envolvimento com outros profissionais da área, verificando-se a necessidade de um prolongamento da formação inicial. Tal procedimento propicia o aperfeiçoamento teórico-prático em seu contexto de trabalho e em termos de visão de mundo, melhorando seu desempenho profissional e atingindo desta forma a necessidade atual que se espera de um docente da área saúde.

Docentes expuseram que os professores mais antigos não eram obrigados a participar do PAP, portanto não participavam - o que é considerado 
um fator negativo, uma vez que o processo de formação docente não se limita ao momento da formação inicial, mas principalmente estende-se por todo o percurso profissional do professor (Freire, 2008).

(...) é obrigatório para todo professor quando ele entra, quando ele é admitido, e a cada seis meses os cursos se repetem (D19).

Os professores antigos eles não são obrigados, mas também eles não participam (D16).

É importante relembrar aos docentes com vasta experiência acadêmica que os professores interessados em transformar sua prática educativa podem se beneficiar imensamente de reuniões com a equipe de colegas. Nesses encontros, de acordo com Freire (2008), ocorrem momentos de trocas de conhecimentos entre os docentes, uma ajuda mútua que proporciona a reeducação no próprio local de trabalho.

Partindo da análise das narrativas dos docentes, acreditamos que se fazem necessários um trabalho coletivo que favoreça o diálogo entre os profissionais e a discussão de pontos de vista diferentes para o amadurecimento de ideias, almejando-se a construção de novos conhecimentos e favorecendo a práxis educativa. Nesse contexto, seriam de extrema importância capacitações docentes para o compartilhamento de conhecimentos no decorrer das práticas educativas e a busca de novas tendências pedagógicas, tendo em vista que o professor precisa de uma teoria que elucide a direção desejada para a prática educativa de humanização do homem, extraída de uma concepção de educação como prática social transformadora (Libâneo, 2009).

Vale destacar, porém, que a formação docente não pode se restringir à participação em cursos eventuais, mas precisa abranger, necessariamente, programas de capacitação, supervisão e avaliação que sejam realizados de forma integrada e permanente.

As dificuldades relatadas e discutidas pelos docentes refletiram diretamente o processo de aprender/ensinar dos alunos da instituição pesquisada. Estudo realizado por Cavalcante (2012) no mesmo cenário da pesquisa aqui tratada indica dificuldades vivenciadas por discentes da instituição no que diz respeito ao processo de ensino/aprendizagem. Os achados da pesquisa apontam para: desarticulações da instituição de ensino com os serviços, profissionais, gestores e comunidade; distanciamento entre teoria e prática; fragmentação e descontextualização do ensino com as práticas em saúde e enfermagem; e uso de metodologias pouco problematizadoras (Cavalcante, 2012).

Contudo, apesar das adversidades evidenciadas pelos docentes no que concerne à implementação de metodologias e métodos ativos no processo de ensino e aprendizagem no âmbito da formação de enfermeiros, alguns 
entrevistados relataram a vontade de mudar, mas sentem dificuldades de enfrentar certas situações dentro da instituição. Vejamos os relatos:

A dificuldade que eu vejo é que aqui, no departamento, geralmente você não tá sozinho numa disciplina, então, às vezes, você quer inovar a disciplina, quer modificar, mas os outros não querem. Os currículos mudam, o projeto pedagógico muda, mas as cabeças das pessoas não mudam (D15).

Então, às vezes, você é novo no ensino, você quer inovar, quer mudar, mas por algo, por uma força política, que já existe na instituição você acaba não conseguindo modificar a sua prática e, aí, continua. O currículo muda e continua se utilizando a metodologia tradicional, e aí a gente observa que o currículo só muda na teoria, mas, na prática, nada muda, porque as cabeças das pessoas não mudam (D20).

A mudança não acontece porque alguns docentes (...) vêm de uma classe social muito confortável e não acreditam no processo de mudança social (D9).

A inserção de pedagogia crítica enfrenta dificuldades no ensino atual, limites esses marcados, conforme Saviani (2010), pela oposição das forças dominantes na sociedade. Nesse sentido, Freire (2010) nos diz que do ponto de vista dos interesses dos dominantes a educação deve ser uma prática imobilizadora e ocultadora de verdades.

As situações denunciadas pelos relatos dos sujeitos provavelmente se perpetuam no contexto do processo de ensino/aprendizagem, porque o novo acarreta, quase sempre, uma ameaça (Rosa, 2007). Ameaça à ordem, ao estabelecido, ao já absorvido e acomodado. Porém, não há mudança sem certa dose de desobediência. Ainda segundo Rosa (2007), quem muda choca e, inevitavelmente, passa a ser alvo de crítica e até de punições. Não existem facilidades para quem se lança a esse desafio, necessitando suportar as pressões existentes para alcançar o objetivo. Infelizmente, é por causa dessas dificuldades encontradas no percurso que muitos desistem, como relata o D12: "Você acaba seguindo a maré, o que não deveria ser."

Diferentemente do que o docente 12 disse com relação a sua prática, corroboramos o posicionamento de Saviani (2010) ao afirmar que o educador precisa ter esperança no país e nas pessoas. Não a esperança ingênua, mas uma esperança crítica, avaliando as condições, a fim de descobrir ideias e estratégias adequadas para intervir nas circunstâncias e modificá-las.

Acredita-se que esse seja o tempo de mudar o sentido das coisas. Talvez em nenhum outro momento de nossa história os caminhos estiveram tão abertos à ação criativa dos próprios educadores, que são cada vez mais solicitados a construírem seus próprios projetos. E por uma razão muito simples: não há modelos preestabelecidos, nem receitas fixas (Rosa, 2007). 


\section{Considerações finais}

As diretrizes contemporâneas para a educação superior demandam pedagogias, metodologias e métodos de ensino que favoreçam a formação de profissionais competentes para atender à nova ordem mundial, cujos potenciais vão além da aquisição de conhecimento cognitivo. A valorização da formação voltada para aquisições de conhecimentos com base na realidade está sendo bastante discutida, o que favorece a aproximação de teoria e prática e exige dos futuros profissionais uma visão crítica com a finalidades de trabalhar com os problemas reais encontrados nos serviços.

No tocante aos profissionais da enfermagem, esse novo contexto requer a formação de enfermeiros ativos, críticos, reflexivos, criativos, sobretudo com a certeza de que o aprendizado é um estado dinâmico e sem limites.

Nessa conjuntura, o reconhecimento das responsabilidades pelas instituições de ensino superior, juntamente com seus docentes, quanto à formação de enfermeiros competentes que atendam às necessidades requeridas pelo contexto atual - aliado à compreensão da importância de pedagogias e metodologias que melhor norteiem a prática docente -, contribui para uma compreensão sobre as atividades do professor com qualidades organizativas, críticas e resolutivas.

Os relatos dos sujeitos do estudo evidenciaram dificuldades vivenciadas por docentes no que diz respeito à utilização de métodos ativos de ensino/aprendizagem na formação do enfermeiro. Tais dificuldades estavam voltadas para problemas curriculares, aplicabilidade de métodos ativos, como também para a resistência de docentes em modificar e atualizar sua prática. Esse fato favorece o uso contínuo de métodos de ensino que não contribui para uma formação de enfermeiros transformadores da realidade social.

Os resultados e as discussões estabelecidas no presente artigo levaram à conclusão de que não é fácil romper com conceitos já internalizados e manifestados em práticas cristalizadas, pois toda mudança gera uma série de sentimentos. Ansiedade, dúvida, medo, insegurança, mas também conhecimento, reflexão, planejamento e esperança marcam esse processo de transição no qual se encontram os sujeitos da presente pesquisa. Tal processo requer tempo, disponibilidade e, principalmente, a vontade do profissional para modificar o seu fazer pedagógico.

Cabe enfatizar que as instituições de ensino e os docentes devem refletir e, com base nessa reflexão, construir novas possibilidades de ações no sentido de modificar ou não o seu contexto de atuação, engajando-se em modelos educacionais que valorizem os aspectos científicos, éticos, pessoais e estéticos, necessários para a condução do processo de ensino em consonância com o novo paradigma pedagógico do ensino superior. 


\section{Colaboradores}

Simone Karine da Costa Mesquita foi responsável pela realização da pesquisa, consolidação dos resultados e elaboração do relatório final; Rejane Millions Viana Meneses, por orientar todo o processo de realização da pesquisa original; Déborah Karollyne Ribeiro Ramos, pela elaboração do manuscrito e aprovação da versão final.

Resumen El estudio tuvo por objetivo identificar las dificultades experimentadas por docentes, en la implementación de metodologías activas, en el curso de pregrado en enfermería de una institución federal ubicada en el estado de Rio Grande do Norte, Brasil. Se trata de una investigación exploratorio-descriptiva con enfoque cualitativo. Las entrevistas semiestructuradas fueron aplicadas a veinte sujetos en los meses de agosto y septiembre del 2011 y, posteriormente, analizadas siguiendo preceptos de análisis de contenido. Las principales adversidades señaladas por los sujetos de la investigación fueron agrupadas en tres categorías de análisis: problemas curriculares como impedimento para la aplicación de metodologías activas de enseñanza/aprendizaje; resistencia del docente en implementar metodologías activas de enseñanza/aprendizaje; y dificultad de comprensión de la aplicabilidad de las metodologías activas de enseñanza/aprendizaje en la práctica docente. Frente a tales dificultades, surgió la necesidad de introducir nuevas formas de organizar y producir el conocimiento, puesto que la utilización de metodologías activas podría favorecer la formación de sujetos con una visión más amplia acerca de la salud, participativos y comprometidos con la transformación de la realidad. Entender la utilización de metodologías activas es fundamental para atender los preceptos del paradigma educativo contemporáneo.

Palabras clave educación; metodologías activas; enseñanza de enfermería; formación del enfermero.

\section{Notas}

1 Prefeitura de São Gonçalo do Amarante, Secretaria Municipal de Saúde, Unidade de Saúde da Família, São Gonçalo do Amarante, Rio Grande do Norte, Brasil.

<simone.karine@hotmail.com>

Correspondência: Rua da Pacificação, 567, bairro Emaús, CEP 59148-800, Parnamirim, Rio Grande do Norte.

2 Universidade Federal do Rio Grande do Norte, Departamento de Enfermagem, Programa de Pós-Graduação em Enfermagem, Natal, Rio Grande do Norte, Brasil. $<$ rejane.millions@yahoo.com.br>

3 Universidade Federal do Rio Grande do Norte, Natal, Rio Grande do Norte, Brasil. $<$ deborah.ribeiro.ramos@gmail.com> 
4 Pesquisa financiada pela Coordenação de Aperfeiçoamento de Pessoal de Nível Superior (Capes). Este artigo é resultado da dissertação de mestrado Abordagens pedagógicas na formação de enfermeiros: compreensão de docentes de enfermagem (2012), de autoria de Simone Karine da Costa Mesquita. Informamos a existência de conflitos de interesses de natureza acadêmica, tendo em vista que os participantes da pesquisa foram os próprios docentes da instituição.

\section{Referências}

AGUILAR-DA-SILVA, Rinaldo H.; ROCHA JUNIOR, Adeir M. Avaliação da problematização como método ativo de ensino-aprendizagem nos cenários de prática do curso de fisioterapia. Revista Científica e-Curriculum, São Paulo, v. 5, n. 20, p. 1-20, 2010. Disponível em: <http://revistas.pucsp.br/index. php/curriculum/article/view/3359/2234>. Acesso em: 18 set. 2013.

BARDIN, Laurence. Análise de conteúdo. Tradução de Luís Antero Reto e Augusto Pinheiro. 70. ed. Lisboa: Edições Loyola, 2010.

BRASIL. Lei n. 9.394/96, de 20 de dezembro de 1996. Estabelece as diretrizes e bases da educação nacional. Diário Oficial da República Federativa do Brasil, Presidência da República, Casa Civil, Subchefia para Assuntos Jurídicos, Brasília, DF, 23 dez. 1996. Seçãol, p. 1. Disponível em: <www.jusbrasil. com.br/diarios/DOU/1996/12/23/Secao-1? $\mathrm{p}=25$ > . Acesso em: 23 fev. 2016.

BULGRAEN, Vanessa C. O papel do professor e sua mediação nos processos de elaboração do conhecimento. Revista Conteúdo, Capivari, v. 1, n. 4, p. 30-38, 2010. Disponível em: <www.conteudo.org.br/index.php/ conteudo/article/viewFile/46/39>. Acesso em: 6 out. 2011 .

CAVALCANTE, Rosangela D. O projeto pedagógico de enfermagem e o Sistema Único de Saúde: a visão de discentes. Interface: Comunicação, Saúde, Educação, Botucatu, v. 16, n. 41, p. 583-584, 2012. Disponível em: $<$ www.scielo.br/pdf/icse/v16n41/a24v16n41. pdf $>$. Acesso em: 18 set. 2013.

CUNHA, Maria I. Docência na universidade, cultura e avaliação institucional: saberes silenciados em questão. Revista Brasileira de Educação, Rio de Janeiro, v. 11, n. 32, p. 258-271, maio-ago. 2006. Disponível em: $<$ http://www.scielo.br/pdf/rbedu/v1ln32/ a05v1ln32.pdf>. Acesso em: 10 jun. 2014.

CYRINO, Eliana G.; TORALLES-PEREIRA, Maria L. Trabalhando com estratégias de ensino-aprendizado por descoberta na área da saúde: a problematização e a aprendizagem baseada em problemas. Cadernos de Saúde Pública, Rio de Janeiro, v. 20, n. 3, p. 780-788, 2004. Disponível em: <www. scielo.br/pdf/csp/v20n3/15.pdf $>$. Acesso em: 18 set. 2013.

FREIRE, Paulo. Conscientização: teoria e prática da libertação - uma introdução ao pensamento de Paulo Freire. 3. ed. São Paulo: Centauro, 2008.

FREIRE, Paulo. Pedagogia da autonomia: saberes necessários à prática educativa. São Paulo: Paz e Terra, 2010.

HECK, Rita M. et al. Uso de metodologia ativa na disciplina gerenciamento de enfermagem em saúde coletiva da FEO/UFPel. Revista Eletrônica de Enfermagem, Goiânia, v. 11, n. 2, p. 429-434, 2009. Disponível em: <www. 
fen.ufg.br/revista/v11/n2/v1ln2a27.htm >. Acesso em: 18 set. 2013.

HENGEMÜHLE, Adelar. Formação de professores: da função de ensinar ao resgate da educação. 2. ed. Rio de Janeiro: Vozes, 2008.

LIBÂNEO, José C. Democratização da escola pública: a pedagogia crítico-social dos conteúdos. 23. ed. São Paulo: Loyola, 2009.

MARIN, Maria J. S. et al. Pós-graduação multiprofissional em saúde: resultados de experiências utilizando metodologias ativas. Interface: Comunicação, Saúde, Educação, Botucatu, SP, v. 14, n. 33, p. 331-344, 2010. Disponível em: <http://dx.doi.org/10.1590/ S1414-32832010000200008>. Acesso em: 4 jul. 2013.

MESQUITA, Simone Karine da Costa. Abordagens pedagógicas na formação de enfermeiros: compreensão de docentes de enfermagem. 2012. 120f. Dissertação (Mestrado em Assistência à Saúde) - Universidade Federal do Rio Grande do Norte, Natal, 2012.

MIRANDA, Simão de. Como se tornar um educador de sucesso: dicas, conselhos, propostas e ideias para potencializar a aprendizagem. Rio de Janeiro: Vozes, 2011.
MITRE, Sandra M. et al. Metodologias ativas de ensino-aprendizagem na formação profissional em saúde: debates atuais. Ciência \& Saúde Coletiva, Rio de Janeiro, v. 13, supl. 2, p. 2.133-2.144, 2008. Disponível em: <www. scielo.br/pdf/csc/v13s2/v13s2a18.pdf $>$. Acesso em: 23 fev. 2016.

PONCE DE LEON, Cassandra G. R. M.; SILVA, César C. Formação de formadores: a prática educativa de um programa de pós-graduação em enfermagem. Revista Brasileira de Enfermagem, Brasília, v. 59, n. 5, p. 636-641, 2006. Disponível em: <http://dx.doi.org/ 10.1590/S003471672006000500008>. Acesso em: 18 set. 2013.

ROSA, Sanny S. Construtivismo e mudança. 10. ed. São Paulo: Cortez, 2007.

SAVIANI, Dermeval. Interlocuções pedagógicas: conversa com Paulo Freire e Adriano Nogueira e 30 entrevistas sobre educação. São Paulo: Autores Associados, 2010.

WALL, Marilene L.; PRADO, Marta L.; CARRARO, Telma E. A experiência de realizar um estágio docência aplicando metodologias ativas. Acta Paulista de Enfermagem, São Paulo, v. 21, n. 3, p. 515-519, 2008. Disponível em: $<$ www.scielo.br/pdf/ape/v2ln3/pt_22.pdf>. Acesso em: 13 set. 2013.

Recebido em 19/09/2013

Aprovado em 15/07/2014 